\title{
Gene expression profiling predicts response to temozolomide in malignant gliomas
}

\author{
ATSUO YOSHINO ${ }^{1}$, AKIYOSHI OGINO ${ }^{1}$, KAZUNARI YACHI ${ }^{1}$, TAKASHI OHTA ${ }^{1}$, \\ TAKAO FUKUSHIMA ${ }^{1}$, TAKAO WATANABE ${ }^{1}$, YOICHI KATAYAMA ${ }^{1}$, \\ YUTAKA OKAMOTO ${ }^{2}$, NORIO NARUSE ${ }^{3}$, EMIKO SANO $^{4}$ and KOUHEI TSUMOTO ${ }^{4}$
}

\author{
${ }^{1}$ Department of Neurological Surgery, Nihon University School of Medicine; ${ }^{2}$ Toray Medical Co., Ltd., Tokyo; \\ ${ }^{3}$ Proteios Research, Inc., c/o Toray Basic Research Laboratories, Kamakura, Kanagawa; ${ }^{4}$ Department of Medical \\ Genome Sciences, Graduate School of Frontier Sciences, The University of Tokyo, Kashiwa, Chiba, Japan
}

Received January 12, 2010; Accepted March 16, 2010

DOI: 10.3892/ijo_00000621

\begin{abstract}
Malignant gliomas are highly lethal neoplasms that cannot be cured with currently available therapies. Temozolomide (TMZ) is a recently introduced alkylating agent that has yielded significant benefits and become a key agent in the treatment of high-grade gliomas. However, its survival benefit remains unsatisfactory. Understanding the molecular basis of TMZ sensitivity/resistance is necessary for improving the treatment outcome by devising strategies that are able to circumvent primary drug resistance. We therefore combined the in vitro TMZ response with microarray gene expression data to identify genes that could potentially be used to predict the response of malignant gliomas to TMZ therapy. We first obtained the individual $\mathrm{IC}_{50}$ values for TMZ in seven malignant glioma cell lines (A-172, AM-38, T98G, U-87MG, U-138MG, U-251MG and YH-13) and then identified the genes whose expression correlated most highly with TMZ sensitivity employing a cDNA microarray. We present here a list of the most highly up-regulated and down-regulated genes which may be involved in conferring TMZ sensitivity/resistance in malignant gliomas, although most of the genes have not been implicated as a causal factor in the TMZ response except MGMT. We also demonstrated and confirmed the $M G M T$ methylation status, quantitative $M G M T$ mRNA levels, and MGMT protein expression levels in TMZ resistant glioma cells in vitro. Our results are thus consistent with previous studies and suggest that a dominant mechanism conferring sensitivity/resistance to TMZ exists in malignant glioma cells. Although the present study dose
\end{abstract}

Correspondence to: Dr Atsuo Yoshino, Department of Neurological Surgery, Nihon University School of Medicine, 30-1 OyaguchiKamimachi, Itabashi-ku, Tokyo 173-8610, Japan

E-mail: ayoshino@med.nihon-u.ac.jp

Key words: malignant glioma, temozolomide, MGMT, methylation, chemotherapy have several limitations, our reported candidate genes could represent not only potential molecular markers for TMZ sensitivity/resistance but also chemotherapy targets. Furthermore, the present study could provide a foundation for alternative therapeutic strategies including novel combination treatments that incorporate additional reagents directed at overcoming resistance to TMZ.

\section{Introduction}

Malignant gliomas are the most frequently occurring primary tumors of the central nervous system and constitute one of the most aggressive and lethal malignancies. They continue to present an enormous therapeutic challenge, because multimodality treatments including extensive tumor resection, radiation therapy and chemotherapy have afforded little improvement to the poor prognosis for more than three decades.

In 2004, the European Organisation for Research and Treatment of Cancer (EORTC)/National Cancer Institute of Canada Clinical Trial Group (NCIC) randomized phase III trial on concomitant and adjuvant temozolomide [TMZ; 3methyl-4-oxo-3,4-dihydroimidazo $(5,1-d)(1,2,3,5)$ tetrazine8 -carboxamide, a relatively new alkylating (methylating) agent], in addition to standard postoperative radiotherapy as the first-line treatment for glioblastomas (the most malignant form of glioma), demonstrated an increase in median survival from 12.1 to 14.6 months and an increase in 2-year survival rate from 10 to $26 \%$ as compared to postoperative radiotherapy alone (1). TMZ has therefore received much attention and become a current standard chemotherapy agent, notably in the treatment of malignant gliomas, although nitrosoureabased chemotherapy had been widely used previously. More recently, EORTC-NCIC reported final results indicating that the benefits of adjuvant TMZ with radiotherapy for glioblastoma lasted throughout five years of follow-up; the overall survival was $9.8 \%$ at five years with TMZ, versus $1.9 \%$ with radiotherapy alone (2). Clearly, concomitant radiation therapy with TMZ chemotherapy followed by adjuvant TMZ treatment can yield meaningful results in glioblastoma patients, but their prognosis remains unsatisfactory. 
The limited efficacy of chemotherapy can be attributed largely to both inherent and acquired tumor drug resistance mechanisms. In addition to $O^{6}$-methylguanine-DNA methyltransferase (MGMT; a protein that removes drug-induced alkylguanine adducts from DNA created by alkylating agents including TMZ), base excision repair (BER) and mismatch repair (MMR) are thought to be involved in the principal mechanisms contributing to TMZ resistance (3-5). Similarly to MGMT, BER plays a crucial role in repairing the cytotoxic methyl DNA adducts, and a high BER activity can confer tumor resistance to TMZ (5). On the other hand, defective DNA MMR can result in tolerance to TMZ regardless of MGMT activity and continuance of DNA replication $(4,5)$. However, some studies have demonstrated resistance to TMZ that was independent of such candidates, suggesting that other major mechanisms were involved in the resistance to TMZ (4,6). Furthermore, tumor chemotherapy resistance may be very complicated, often multifactorial and with many genes involved. The resistance of glioblastomas to TMZ appears to follow a more complex pattern than simple dependence on $M G M T$ levels $(7,8)$, although its detailed regulation at the genomic level remains poorly understood.

With the recent development of high-density oligonucleotide DNA array technology, global gene expression profiles can be analyzed simultaneously (9). In addition to the identification of new classes of human malignancies, this powerful method has become widely applied in attempts to increase our understanding of chemotherapy resistance and to provide further information about the underlying tumor biology that can be used to guide therapeutic strategies $(5,10)$. Thus, in the present study, to gain new insights into the mechanisms of TMZ sensitivity/resistance in malignant gliomas and to identify new marker and target genes involved in malignant glioma pathogenesis and new therapeutic strategies for TMZ, we attempted to identify specific gene expression signatures associated with pre-existing sensitivity/resistance to TMZ employing the cDNA microarray technique.

\section{Materials and methods}

Tumor cell lines, cell culture and TMZ sensitivity determination. Human malignant glioma U-87MG and U-138MG cells were purchased from the American Tissue Culture Collection (ATCC; Manassas, VA, USA) and A-172, AM-38, T98G, U-251MG and YH-13 cells were purchased from Health Science Research Resources Bank (Sennann, Osaka, Japan). Cells were cultured in Dulbecco's modified Eagle's medium (DMEM, Gibco BRL, Grand Island, NY, USA) supplemented with $10 \%$ fetal bovine serum (Gibco BRL) in a standard humidified incubator at $37^{\circ} \mathrm{C}$ under a $5 \% \mathrm{CO}_{2}, 95 \%$ air atmosphere.

The sensitivities of the seven glioma cell lines to TMZ were evaluated from the concentration required for $50 \%$ growth inhibition $\left(\mathrm{IC}_{50}\right.$; also known as $\mathrm{GI}_{50}$ ) in comparison with untreated controls. Briefly, cells were plated at $1 \times 10^{4}$ or $2 \times 10^{4}$ cells per well in 24-well, flat-bottomed plates and incubated with medium for $24 \mathrm{~h}$. The cells were subsequently washed twice with medium and incubated further with fresh medium (control) or medium containing 0.1-1,000 $\mu \mathrm{M}$ of TMZ. After exposure to the various concentrations of TMZ for $72 \mathrm{~h}$, cells were detached by trypsinization and the numbers counted. The experiments were repeated at least four times at each concentration.

RNA preparation and hybridization to GeneChip array. The cell lines were subjected to an assessment of their gene expression profile using a high-density oligonucleotide array (GeneChip array; Affymetrix, Santa Clara, CA, USA) as described previously (11). Briefly, the extracted total RNA was purified with an RNeasy mini kit (Qiagen, Valencia, CA), quantified by spectrophotometry and analyzed by gel electrophoresis. Double-stranded cDNA was generated from the total RNA $(5 \mu \mathrm{g})$ using a One-Cycle cDNA synthesis kit (Affymetrix). Biotinylated cRNA from cDNA was synthesized in an in vitro transcription reaction employing an IVT labeling kit (Affymetrix). The biotinylated cRNA (10 $\mu \mathrm{g})$ was then fragmented and hybridized to a DNA oligonucleotide expression array (Affymetrix Human Genome U133A 2.0 Array) containing greater than 22,277 probe sets for approximately 14,500 human genes (some genes are represented on the array by multiple probe sets). The hybridized probe array was washed and stained with a streptavidinphycoerythrin conjugate (Molecular Probe, Eugene, OR, USA) using a Fluidics Station 450 (Affymetrix), following the manufacturer's instructions.

Identification of discriminatory genes. The probe array was then scanned with a confocal laser scanner (GeneChip Scanner 3000; Affymetrix) and analyzed with Affymetrix GeneChip Operating Software 1.1 to calculate the signal intensity of the gene expression levels. All of the genes represented on the GeneChip were globally normalized and scaled to signal intensity (gene expression value) as described previously (12). To avoid contributions from artificial sources of variation in the experimentally measured expression patterns, each cell line was grown in three independent cultures, and the entire process was carried out independently on mRNA extracted from each culture. The expression array analysis for each cell line was then run in triplicate.

To identify discriminative genes for TMZ sensitivity/ resistance, Pearson's correlation was performed to evaluate the association between the $\mathrm{IC}_{50}$ (sensitivity) of $\mathrm{TMZ}$ and gene expression level of each gene $(22,277$ probe sets for approximately 14,500 human genes), and Spearman's rank correlation coefficient was also calculated to confirm Pearson's correlation coefficient (Microsoft Office Excel 2007).

MGMT status. The correlations among the MGMT methylation status, quantitative levels of MGMT mRNA and MGMT protein expression were assessed in seven glioma cell lines, since one of the most prominent resistance mechanisms to TMZ has been widely considered to be the action of the DNA repair enzyme MGMT (7,13-15).

i) Detection of MGMT methylation. Promoter hypermethylation of the MGMT gene was determined by the methylationspecific polymerase chain reaction (MS-PCR) (16). The PCR was performed with primers specific for either methylated or modified unmethylated DNA, as described previously (17-19). 
Briefly, the DNA was extracted using a QIAamp ${ }^{\circledR}$ DNA Mini Kit (Qiagen), and then $1 \mu \mathrm{g}$ of extracted DNA underwent bisulfite modification using a CpGenome ${ }^{\mathrm{TM}}$ DNA Modification Kit (Chemicon, Millipore Corp., Billerica, MA, USA), according to the manufacturer's instructions. Amplified products were electrophoresed on $3 \%$ agarose gels, and were visualized with ethidium bromide. Enzymatically methylated human male genomic DNA (CpGenome Universal Methylated DNA; Chemicon, Millipore Corp.) and DNA from normal lymphocytes were included in each set of the PCR as methylated and unmethylated controls, respectively.

ii) Quantitation of MGMT $m R N A$ by real-time quantitative $R T-P C R$. Quantitation of the MGMT gene expression was performed by the real-time quantitative reverse transcriptionPCR (RT-PCR) method, as developed recently $(20,21)$. Briefly, the real-time PCR reaction mixture was prepared using a TaqMan Universal Master Mix (Applied Biosystems, CA, USA), $120 \mathrm{nM}$ of each $M G M T$ primer, $200 \mathrm{nM}$ probe (5'-CGA GCA GTG GGA GGA GCA ATG AGA-3'), and $2.5 \mu 1$ of each cDNA sample. The PCR conditions were as follows: 1st stage, $95^{\circ} \mathrm{C}$ for $10 \mathrm{~min}$; 2nd stage, 45 cycles at $95^{\circ} \mathrm{C}$ for $30 \mathrm{sec}, 60^{\circ} \mathrm{C}$ for $30 \mathrm{sec}$, and $72^{\circ} \mathrm{C}$ for $30 \mathrm{sec}$; and 3rd stage, $72^{\circ} \mathrm{C}$ for $10 \mathrm{sec}$, employing a real-time PCR system (ABI PRISM 7900HT Sequence Detection System; Applied Biosystems). Glyceraldehyde-3-phosphatase dehydrogenase $(G A P D H)$ mRNA expression levels were used as the quantitative internal control. Standard curves for $M G M T$ and GAPDH mRNA were generated employing 10 -fold serially diluted standard plasmid clones inserted by MGMT or GAPDH PCR products as templates, and the amount of each mRNA expression level was calculated from the relevant standard curve. For precise quantification, the $M G M T$ mRNA expression level of each sample was normalized using the expression of the GAPDH gene.

iii) Western blot analysis of MGMT. To determine the protein levels of MGMT, Western blot analysis was employed as described previously $(22,23)$. Briefly, soluble protein lysates of glioma cells were obtained employing lysis buffer (Medical \& Biological Laboratories, Woburn, MA, USA) for $20 \mathrm{~min}$ on ice. Portion $(5 \mu \mathrm{g})$ of these proteins was loaded and separated by $12.5 \%$ polyacrylamide gel electrophoresis, and then transferred onto nitrocellulose membranes (Bio-Rad Laboratories, Franklin Lakes, NJ, USA) for $30 \mathrm{~min}$ at $10 \mathrm{~V}$ with a Bio-Rad transblot (Bio-Rad Laboratories). Nonspecific binding was blocked with a wash buffer (PBS/ $0.05 \%$ Tween-20) containing 5\% ECL blocking agent (GE Healthcare UK Ltd., Amersham Place, Little Chalfont, Buckinghamshire, UK) for $60 \mathrm{~min}$. The primary antibodies and dilutions used for the immunoblotting were MGMT (1:200) (MT 3.1; Neomarkers, Fremont, CA, USA) for $120 \mathrm{~min}$ and ß-actin (1:5000) (AC-15; Sigma-Aldrich, St. Louis, MO, USA) for $60 \mathrm{~min}$. The secondary antibodies employed were biotinylated anti-mouse $\mathrm{IgG}$ ( $\mathrm{H}$ and L) (1:1000) (BA-2000; Vector Laboratories, Burlingame, CA, USA) for $60 \mathrm{~min}$. The immunoblotted complex was visualized with the aid of an ECL Western blotting analysis system (GE Healthcare UK Ltd.).

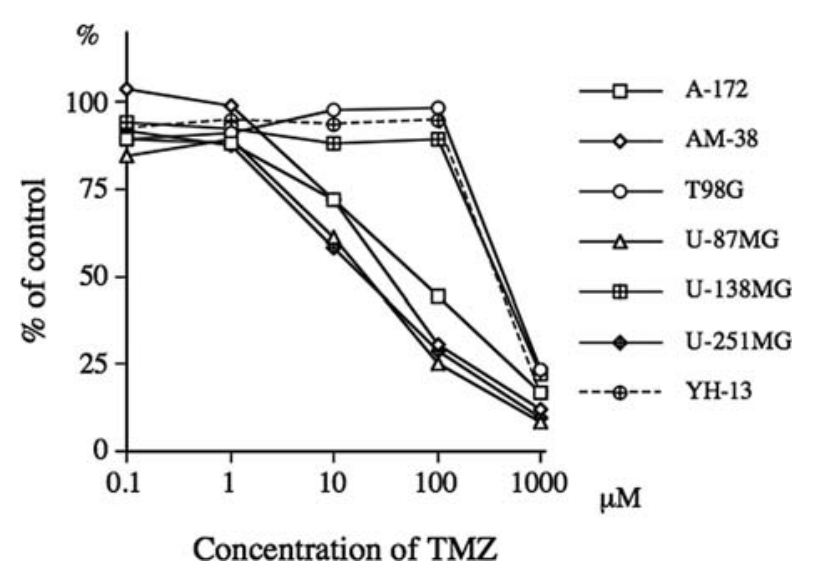

Figure 1. Antitumor effects of TMZ against seven human glioma derived cell lines. At $72 \mathrm{~h}$ after addition of TMZ (final concentration, 0-1,000 $\mu \mathrm{M}$ ) to the culture medium, the number of viable cells was counted. The number was expressed as a percentage of the untreated control.

Table I. $\mathrm{IC}_{50}$ of temozolomide for seven malignant glioma cell lines.

\begin{tabular}{lc}
\hline Cell line & $\mathrm{IC}_{50}(\mu \mathrm{M})$ \\
\hline A-172 & 52.4 \\
AM-38 & 40.7 \\
T98G & 441.6 \\
U-87MG & 23.0 \\
U-138MG & 387.3 \\
U-251MG & 22.5 \\
YH-13 & 371.3 \\
\hline
\end{tabular}

The $\mathrm{IC}_{50}$ (mean), represents the temozolomide concentration required for a $50 \%$ decrease in cell growth compared to the control.

\section{Results}

We first obtained the individual $\mathrm{IC}_{50}$ values of $\mathrm{TMZ}$ (sensitivity/resistance) from the cell growth inhibitory effects of the seven malignant glioma cell lines, and then identified the genes whose expression correlated most highly with TMZ sensitivity/resistance employing the GeneChip array and Pearson's correlation coefficient.

$I C_{50}$ of TMZ in glioma cell lines. To evaluate the antitumor effects of TMZ in malignant glioma cells, we treated the seven malignant glioma cell lines with $0-1,000 \mu \mathrm{M}$ of TMZ for $72 \mathrm{~h}$, and assessed the numbers of viable cells. As shown in Fig. 1, cell growth inhibitory effects of TMZ on all the tumor cell lines were observed in a dose-dependent manner. The $\mathrm{IC}_{50}$ of $\mathrm{TMZ}$ for four malignant glioma cells (A-172, AM-38, U-87MG and U-251MG) was $<100 \mu \mathrm{M}$, although T98G, U-138MG and YH-13 cells were found to be resistant to $\mathrm{TMZ}\left(\mathrm{IC}_{50}>350 \mu \mathrm{M}\right)$. The $\mathrm{IC}_{50}$ values of $\mathrm{TMZ}$ for each cell line are listed in Table I. 
Table II. The 15 negative and 15 positive differentially expressed genes associated with TMZ sensitivity.

\begin{tabular}{|c|c|c|c|}
\hline Symbol & Gene title & Correlation & P-value \\
\hline ATXN10 & Ataxin 10 & 0.965 & $<0.0001$ \\
\hline EIF4ENIF1 & Eukaryotic translation initiation factor 4E nuclear import factor 1 & 0.934 & $<0.0001$ \\
\hline MGMT & $O^{6}$-methylguanine-DNA methyltransferase & 0.924 & $<0.0001$ \\
\hline LPAR1 & Lysophosphatidic acid receptor 1 & 0.905 & $<0.0001$ \\
\hline LAMB 1 & Laminin, $ß 1$ & 0.898 & $<0.0001$ \\
\hline MDK & Midkine (neurite growth-promoting factor 2) & 0.898 & $<0.0001$ \\
\hline SECTM1 & Secreted and transmembrane 1 & 0.897 & $<0.0001$ \\
\hline GTPBP1 & GTP binding protein 1 & 0.897 & $<0.0001$ \\
\hline UGDH & UDP-glucose dehydrogenase & 0.891 & $<0.0001$ \\
\hline ZNF354A & Zinc finger protein $354 \mathrm{~A}$ & 0.889 & $<0.0001$ \\
\hline CASP1 & Caspase 1 , apoptosis-related cysteine peptidase & 0.888 & $<0.0001$ \\
\hline VDR & Vitamin D (1,25-dihydroxyvitamin D3) receptor & 0.882 & $<0.0001$ \\
\hline RBM9 & RNA binding motif protein 9 & 0.881 & $<0.0001$ \\
\hline RYBP & RING1 and YY1 binding protein & 0.881 & $<0.0001$ \\
\hline HMG2L1 & High-mobility group protein 2-like 1 & 0.877 & $<0.0001$ \\
\hline FAM57A & Family with sequence similarity 57 , member A & -0.885 & $<0.0001$ \\
\hline ZNF365 & Zinc finger protein 365 & -0.870 & $<0.0001$ \\
\hline HIST3H2A & Histone $3, \mathrm{H} 2 \mathrm{a}$ & -0.854 & $<0.0001$ \\
\hline ECD & Ecdysoneless homolog & -0.835 & $<0.0001$ \\
\hline CYFIP2 & Cytoplasmic FMR1 interacting protein 2 & -0.831 & $<0.0001$ \\
\hline LHFPL2 & Lipoma HMGIC fusion partner-like 2 & -0.829 & $<0.0001$ \\
\hline WDR37 & WD repeat domain 37 & -0.815 & $<0.0001$ \\
\hline MCM6 & Minichromosome maintenance deficient 6 & -0.813 & $<0.0001$ \\
\hline PDE4DIP & Phosphodiesterase 4D interacting protein & -0.813 & $<0.0001$ \\
\hline WIPF2 & WAS/WASL interacting protein family, member 2 & -0.811 & $<0.0001$ \\
\hline PARD3 & par-3 partitioning defective 3 homolog & -0.811 & $<0.0001$ \\
\hline PCMT1 & Protein-L-isoaspartate (D-aspartate) O-methyltransferase & -0.811 & $<0.0001$ \\
\hline MLXIP & MLX interacting protein & -0.807 & $<0.0001$ \\
\hline PIP4K2A & Phosphatidylinositol-5-phosphate 4-kinase, type II, $\alpha$ & -0.806 & $<0.0001$ \\
\hline CCDC109B & Coiled-coil domain containing 109B & -0.800 & $<0.0001$ \\
\hline
\end{tabular}

Identification of discriminatory genes. From the total of 22,277 probe sets, no expressed gene was omitted, leaving 16,913 probe sets for subsequent analysis. Several upregulated and down-regulated genes in the seven malignant glioma cell lines relative to their TMZ sensitivity were observed. The highly significant statistically negative and positive correlation of genes associated with TMZ sensitivity are indicated in Tables II and III. Pearson's correlation coefficient ( $r$ ) and the corresponding P-values for these correlations are also shown in Tables II and III (the positive and negative higher rank of Pearson's correlation coefficient, and a parametric $\mathrm{P}<0.00001$, are listed in Tables II and III). The gene-specific information was retrieved from Entrez gene: gene-centered information at NCBI (24).

Most of the genes indicated in Table II have not, to our knowledge, been previously suspected to play a role in the prediction of TMZ sensitivity/resistance, chemotherapy sensitivity, or prognosis. However, the MGMT expression level was significantly positively correlated with TMZ resistance (Pearson's correlation coefficient and the corresponding P-values were 0.924 and $<0.0001$, respectively), and confirmed the capacity of MGMT to predict the sensitivity/resistance of TMZ in malignant glioma cell lines. Further four genes [namely, midkine $(M D K)$, caspase $1(C A S P 1)$, vitamin D receptor $(V D R)$, and protein-L-isoaspartate O-methyltransferase $(P C M T 1)]$, for which the results were significantly correlated in our analyses (with $M D K, C A S P 1$ and $V D R$ being positively correlated to TMZ resistance, and PCMT1 negatively correlated to TMZ resistance) (Fig. 2), have previously been reported to be associated with chemotherapy resistance, prognosis, tumor progression, or antiproliferation, in malignant gliomas (25-29).

We also mapped the selected features to chromosomes (Tables III and IV). The chromosomal locus 22q13 was 


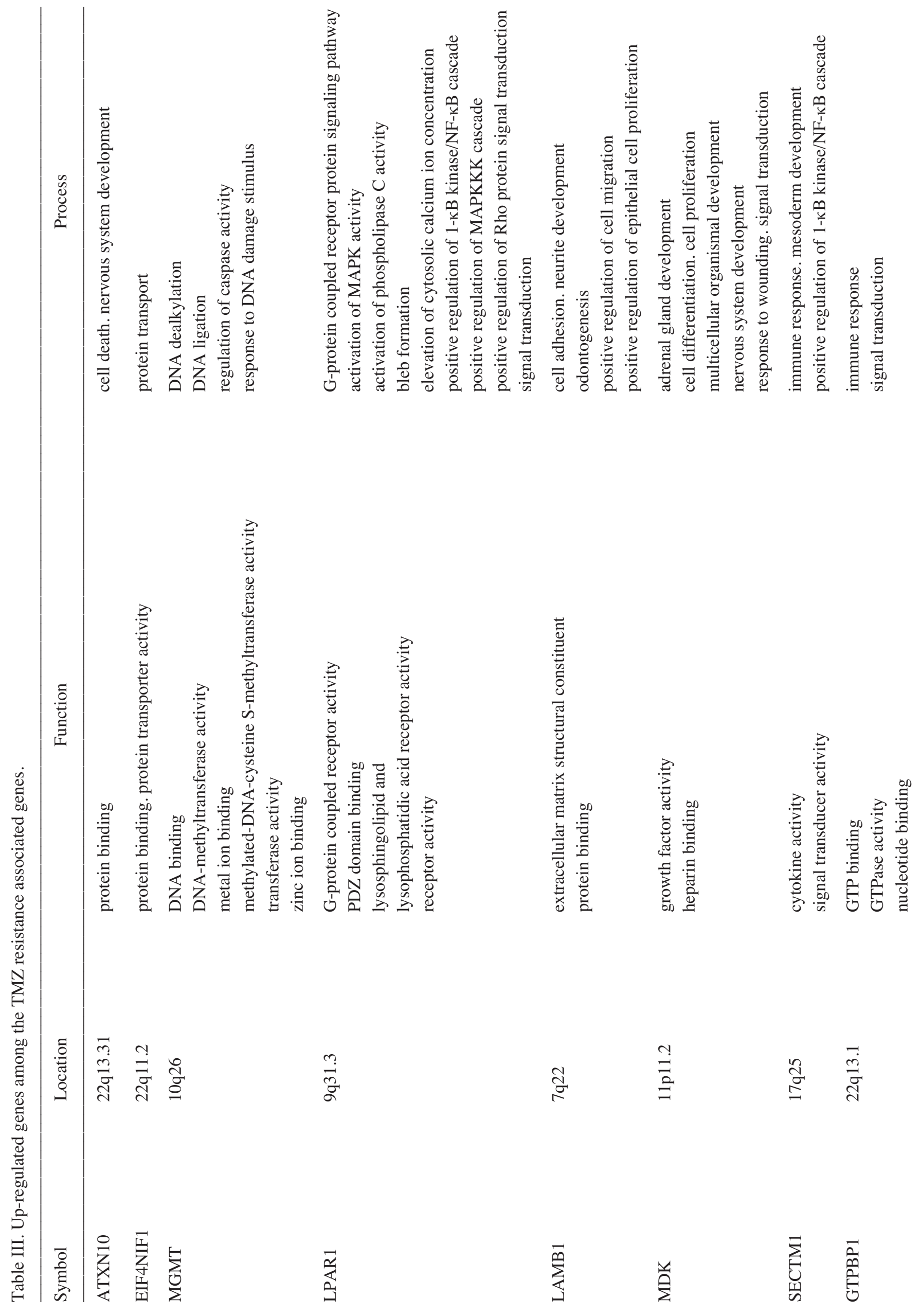




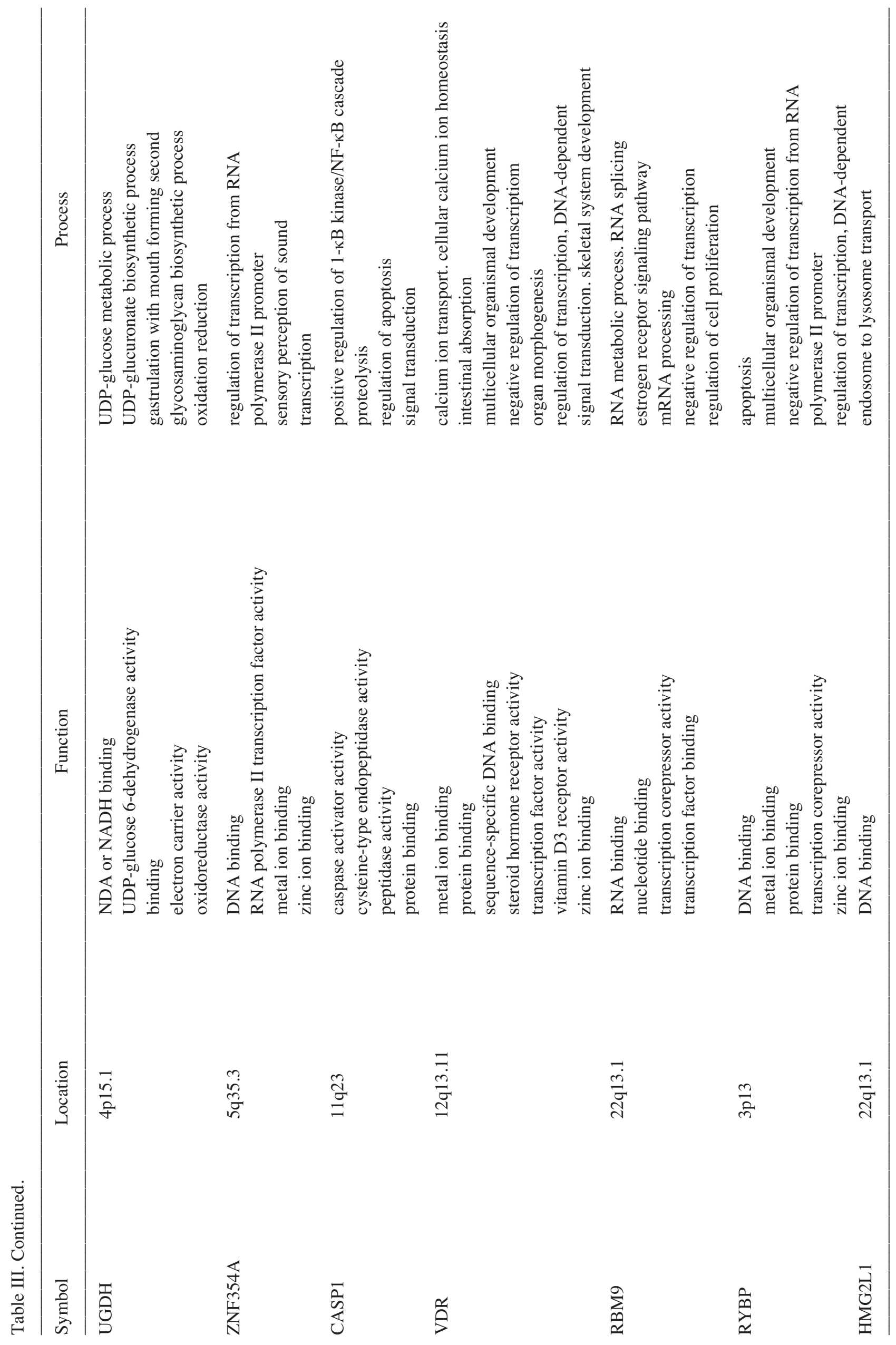


Table IV. Down-regulated genes in TMZ resistance associated genes.

\begin{tabular}{|c|c|c|c|}
\hline Symbol & Location & Function & Process \\
\hline FAM57A & $17 \mathrm{p} 13.3$ & & \\
\hline ZNF365 & $10 \mathrm{q} 21.2$ & $\begin{array}{l}\text { protein binding } \\
\text { zinc ion binding }\end{array}$ & \\
\hline HIST3H2A & $1 \mathrm{q} 42.13$ & DNA binding & nucleosome assembly \\
\hline $\mathrm{ECD}$ & $10 \mathrm{q} 22.1$ & transcription coactivator activity & $\begin{array}{l}\text { regulation of glycolysis } \\
\text { regulation of transcription, DNA-dependent } \\
\text { transcription from RNA polymerase II promoter }\end{array}$ \\
\hline CYFIP2 & $5 q 33.3$ & protein binding & $\begin{array}{l}\text { apoptosis } \\
\text { cell-cell adhesion }\end{array}$ \\
\hline LHFPL2 & $5 q 14.1$ & & \\
\hline WDR37 & $10 \mathrm{p} 15.3$ & & \\
\hline MCM6 & $2 q 21$ & $\begin{array}{l}\text { ATP binding } \\
\text { DNA binding } \\
\text { DNA helicase activity } \\
\text { identical protein binding } \\
\text { nucleotide binding } \\
\text { single-strand DNA binding }\end{array}$ & $\begin{array}{l}\text { DNA replication } \\
\text { DNA replication initiation } \\
\text { DNA unwinding during replication } \\
\text { cell cycle } \\
\text { regulation of transcription, DNA-dependent } \\
\text { transcription }\end{array}$ \\
\hline PDE4DIP & $1 q 12$ & & \\
\hline WIPF2 & $17 \mathrm{q} 21.2$ & actin binding & \\
\hline PARD3 & 10p11.2-p11.21 & protein binding & $\begin{array}{l}\text { activation of protein kinase } \mathrm{C} \text { activity by } \\
\text { G-protein coupled receptor protein } \\
\text { signaling pathway } \\
\text { asymmetric cell division } \\
\text { axonogenesis } \\
\text { cell cycle } \\
\text { establishment or maintenance of cell polarity }\end{array}$ \\
\hline PCMT1 & $6 q 24-q 25$ & $\begin{array}{l}\text { identical protein binding } \\
\text { methyltransferase activity } \\
\text { protein-L-isoaspartate (D-aspartate) } \\
\mathrm{O}^{6} \text {-methyltransferase activity } \\
\text { transferase activity }\end{array}$ & $\begin{array}{l}\text { protein complex assembly } \\
\text { protein amino acid methylation } \\
\text { protein modification process } \\
\text { protein repair }\end{array}$ \\
\hline MLXIP & $12 \mathrm{q} 24.31$ & $\begin{array}{l}\text { DNA binding } \\
\text { transcription regulator activity }\end{array}$ & regulation of transcription, DNA-dependent \\
\hline PIP4K2A & $10 \mathrm{p} 12.2$ & $\begin{array}{l}\text { 1-phosphatidylinositol-4-phosphate } \\
\text { 5-kinase activity } \\
\text { 1-phosphatidylinositol-4-phosphate } \\
\text { 4-kinase activity } \\
\text { ATP binding } \\
\text { kinase activity } \\
\text { nucleotide binding } \\
\text { transferase activity }\end{array}$ & $\begin{array}{l}\text { phosphatidylinositol metabolic process } \\
\text { phosphorylation }\end{array}$ \\
\hline CCDC109B & $4 q 25$ & & \\
\hline
\end{tabular}



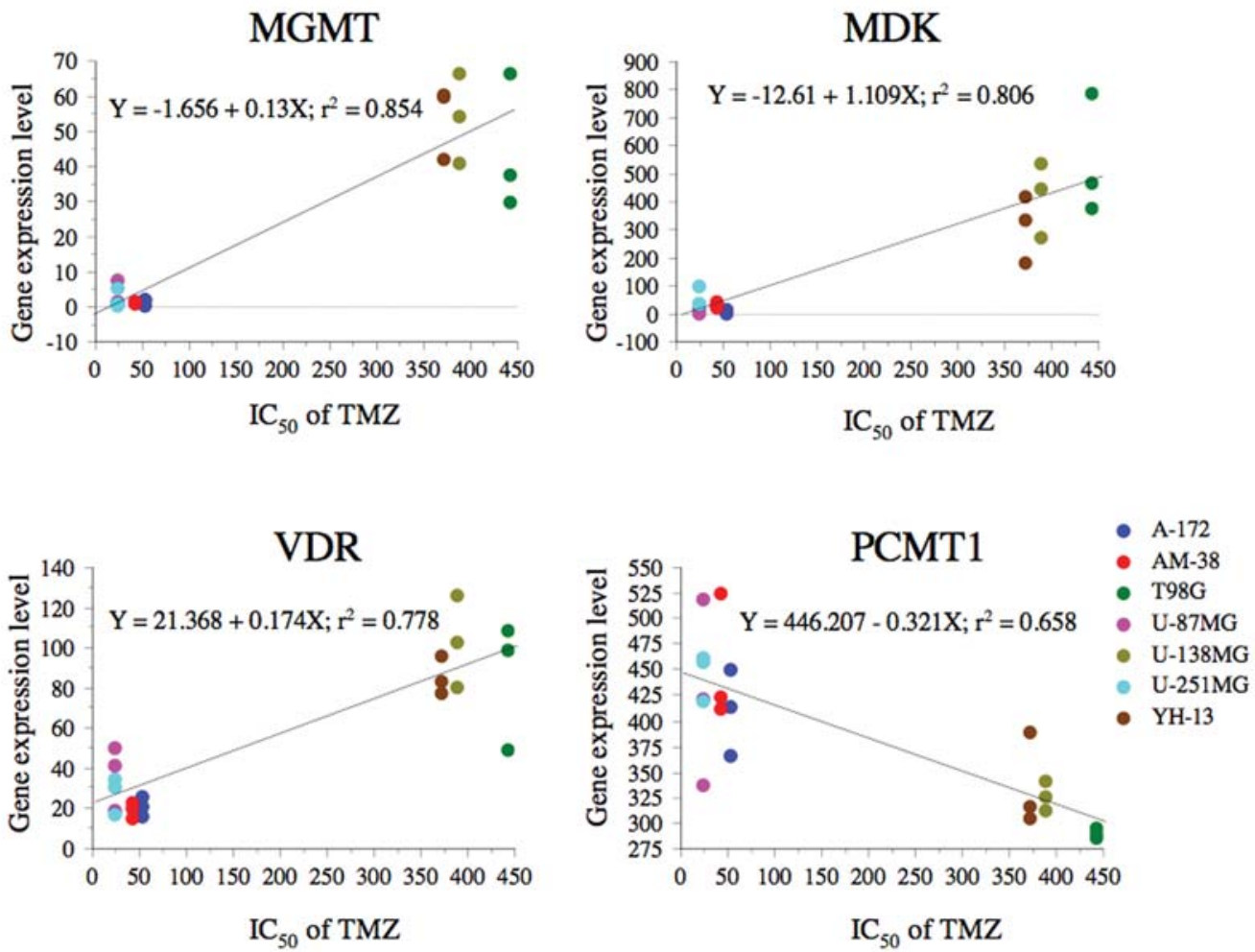

Figure 2. Relationship between gene expression levels $(M G M T, M D K, V D R$, and $P C M T 1)$ and TMZ sensitivity ( $\mathrm{IC}_{50}$ of TMZ) of seven malignant glioma cell lines.

Table V.MGMT methylation status, quantitative of MGMT mRNA, and MGMT protein expression in seven malignant glioma cell lines.

\begin{tabular}{lccccccc}
\hline & A-172 & AM-38 & T98G & U-87MG & U-138MG & U-251MG & YH-13 \\
\hline$M G M T$ methylation status & M & M & M, U & M & U & M, U & U \\
Quantitative $M G M T$ mRNA & ND & ND & $5.9 \times 10^{3}$ & ND & $6.3 \times 10^{3}$ & ND & $5.4 \times 10^{3}$ \\
(copy $/ \mu$ g RNA) & ND & ND & + & ND & + & ND & + \\
MGMT protein expression & + & & & & &
\end{tabular}

M, methylated; U, unmethylated; ND, not detected; +, expression.

suspected to be a potential hotspot for aberrant gene expression associated with TMZ resistance in malignant glioma cell lines.

Correlations of TMZ sensitivity with MGMT methylation status, quantitative MGMT mRNA expression and MGMT protein expression. As shown in Fig. 2, a significant correlation $\left(\mathrm{P}<0.0001, \mathrm{r}^{2}=0.854\right)$ was noted between TMZ sensitivity and the $M G M T$ gene expression detected with the high-density oligonucleotide microarray (HG-U133A 2.0, Affymetrix). The MGMT status of the seven malignant glioma cell lines was also determined by the MGMT methylation status, quantitative $M G M T$ mRNA expression, and MGMT protein expression. Methylation of the $\mathrm{CpG}$ islands in promoter regions is a major factor in gene regulation and is correlated with transcriptional silencing. To examine the MGMT methylation status, DNA from the present seven malignant glioma cell lines was isolated and investigated by performing the MS-PCR. Furthermore, in order to confirm whether or not MGMT expression might be responsible for part of the resistance mechanism to TMZ in glioma cells, we tested the MGMT expression at the mRNA and protein levels.

Parts of the results obtained have recently been reported elsewhere $(22,23)$. Promoter hypermethylation of $M G M T$ was demonstrated in A-172, AM-38 and U-87MG cells (TMZ sensitive cell lines) but not in U-138MG and YH-13 cells (TMZ resistant cell lines). The other two cell lines, 
T98G and U-251MG, appeared to contain methylated and unmethylated DNA at this locus. Furthermore, MGMT expression as determined from the MGMT mRNA expression levels using the real-time quantitative RT-PCR and Western blot analysis was not detected in the TMZ sensitive cell lines, A-172, AM-38, U-87MG and U-251MG. In contrast, such expression was detected in the TMZ-resistant cell lines, T98G, U-138MG and YH-13. The absolute values of MGMT mRNA normalized to the level of GAPDH in T98G, U-138MG and $\mathrm{YH}-13$ cells were $5.9 \times 10^{3}, 6.3 \times 10^{3}$ and $5.4 \times 10^{3} \mathrm{copy} / \mu \mathrm{g}$ RNA, respectively (Table V). These findings suggested that the resistance of T98G, U-138MG and YH-13 cells to TMZ is probably related to MGMT.

\section{Discussion}

It is possible that large-scale gene expression analysis, rather than an analysis of a single gene or pathway, can yield a more robust predictor of malignant glioma responses to TMZ, since it would involve the analysis of genes associated with multiple mechanisms of resistance $(5,8)$. In this study, we evaluated the gene expression profiles employing GeneChip in seven malignant human glioma-derived cell lines in an attempt to identify marker(s) that could be used clinically to predict the response of malignant gliomas to TMZ therapy. Since the gene expression profiles were determined in untreated cells, our data relate to the sensitivity/resistance to TMZ therapy rather than to the molecular consequences of therapy (30).

Resistance to TMZ therapy is thought to arise when the methylated DNA bases are repaired by MGMT (13) or BER (31), or when the MMR pathway is deficient (32), or the damaged DNA is tolerated $(4,5)$. Notably, glioblastoma patients with promoter hypermethylation of the MGMT gene that silences its expression have been shown to benefit from TMZ therapy (2,33-35). In the present study, as expected, our results indicated that an elevated expression of the MGMT gene is one of the most robust predictors of the TMZ response in malignant glioma cells. We also demonstrated and confirmed the MGMT protein expression levels and quantitative MGMT mRNA levels in TMZ resistant, T98G, U-138MG and YH-13 cells. Furthermore, the MGMT promoter methylation observed in nearly half of the seven malignant glioma cell lines analyzed in this study corresponded with the observed expression of MGMT protein, MGMT mRNA and TMZ sensitivity/resistance. Our findings are thus consistent with previous studies and suggest that a dominant mechanism conferring sensitivity/resistance to TMZ exists in malignant glioma cells $(2,13,14,20,34,35)$. On the other hand, a differential gene expression was not clearly identified for BER and MMR genes in the present study. Although BER can repair N-methylated lesions generated by alkylating agents such as TMZ $(5,36)$, our results suggest that this pathway is likely to have a minimal effect on TMZ resistance in malignant glioma cell lines. Moreover, our data corroborate the finding of Maxwell et al that MMR deficiency does not appear to be responsible for mediating $\mathrm{TMZ}$ resistance in malignant gliomas (4).

The Affymetrix Human Genome U133A 2.0 Array also contains the well-known multi-drug resistance candidate genes and other genes involved in drug resistance mechanisms including drug-metabolism and detoxification $(37,38)$. However, we did not identify any of those genes to be strongly associated with the TMZ response in malignant gliomas. Ma et al found that tumor cell-acquired resistance to TMZ was associated with an increased MGMT activity and alterations of apoptosis-controlling proteins, i.e., reduced Bad, Bax and Bcl-Xs, in a human glioma cell line (39). However, again, none of these genes were identified in our microarray analysis. On the other hand, highly significant statistically positive- and negative-correlation of genes concerned with TMZ sensitivity/resistance were found as shown in Tables II and III. To our knowledge, 25 of these 30 genes have not been reported previously to be associated with chemotherapy resistance, prognosis, tumor progression, or antiproliferation, in malignant gliomas. The other five genes, four up-regulated genes (MGMT, MDK, CASPI and VDR) and one downregulated $(P C M T 1)$ gene, that have been reported previously to have such associations (chemotherapy resistance, MGMT and $M D K$; prognosis, $M G M T$ and $M D K$; tumor progression, $M D K$ and $P C M T 1$; antiproliferation, $M D K$ and $V D R$; and other associations, CASPI) (25-29), were differentially expressed in association with $\mathrm{TMZ}$ sensitivity/resistance in the glioma-derived cell lines. Among the genes positively correlated to $\mathrm{TMZ}$ resistance in our analysis, one of the most noteworthy is $M G M T$, as mentioned above; MGMT expression provides a resistance measure that can potentially be applied to current TMZ-based treatment strategies for malignant glioma patients. Depletion of MGMT by the substrate analogue inhibitor $O^{6}$-benzylguanine or by interferon- $\beta$ (which is known to exhibit pleiotropic biological activities including antitumor effects) has yielded encouraging results and suggests a therapeutic potential for chemotherapy in combination with such a resistance modulator for the treatment of malignant gliomas $(5,13,23,40,41)$. However, although a phase II clinical trial has indicated that $O^{6}$ benzylguanine is able to restore TMZ sensitivity in patients with TMZ-resistant anaplastic gliomas, there appeared to be no significant restoration of TMZ sensitivity in patients with TMZ resistant glioblastoma (42).

Following the introduction of the current standard treatment involving concomitant radiation plus TMZ followed by adjuvant TMZ, two significant papers on the analysis of glioblastoma-derived gene expression profiles to TMZ resistance were published. Bredel et al highlighted the involvement of a cellular pathway of nuclear factor- $\kappa \mathrm{B}$ $(\mathrm{NF}-\kappa \mathrm{B}$, which is activated in response to DNA damage caused by $O^{6}$-alkylating agents), especially the zinc finger protein tumor necrosis factor- $\alpha$-induced protein 3 (TNFAIP3, a potent inhibitor of $\mathrm{NF}-\mathrm{\kappa B}$ signaling), mediating resistance to $O^{6}$-alkylating agents in glioblastoma cells (8). Excessive and prolonged activation of $\mathrm{NF}-\kappa \mathrm{B}$ has been suggested as a principal mechanism of tumor chemoresistance, which is primarily mediated by its antiapoptotic activity $(43,44)$, and some evidence has also indicated a link between the NF-kB pathway and resistance of glioblastoma cells to $O^{6}$-alkylating agents (45). The consistent up-regulated genes of this pathway in our study (LPAR1, SECTM1 and CASP1, a positive regulator of the $1-\kappa \mathrm{B}$ kinase/NF- $\mathrm{KB}$ cascade) suggest a potentially important role for his pathway in the development 
of resistance to TMZ in glioblastoma cells. Murat et al (46), in the other significant paper, reported an analysis of glioblastoma-derived gene expression profiles from patients treated in two prospective clinical trials $(1,47)$. They suggested that the homeobox gene $(H O X)$, which comprises Prominin-1 (CD133; CD133 positivity has been postulated to be a glioma stem-cell marker), and epidermal growth factor receptor gene $(E G F R)$ expression were independent prognostic factors in a multivariate analysis adjusted for $M G M T$ methylation status and age, although epigenetic inactivation of the MGMT gene promoter remained the most prominent predictive factor.

On the other hand, many new antitumor drugs are being developed that target-specific molecular or genetic lesions, and although targeted therapies alone do not often demonstrate sufficient antitumor effects, it seems likely that when combined with standard chemotherapies, the responses could be higher and more durable (5). Thus, our reported genes (especially $M D K, C A S P 1, V D R$ and $P C M T 1$ ) and pathway (the NF- $\mathrm{B}$ pathway) may represent not only potential molecular markers for TMZ sensitivity/resistance but also attractive targets for therapeutic modulation of glioblastomas. Furthermore, the present study could provide a foundation for alternative therapeutic strategies including novel combination treatments that incorporate additional reagents directed at overcoming resistance to TMZ.

Finally, several limitations of the present study should be briefly mentioned. First, it can always be viewed that the expression profiles of cell lines which have undergone many passages do not exactly represent the genetic events that occur in actual tumors (48). Second, the present study was restricted to the use of only seven glioma cell lines. Third, it is possible that if the entire genome were to be analyzed, the number of potential molecular markers for TMZ sensitivity/ resistance and chemotherapy targets would increase (9). Fourth, in general, the gene expression correlation of drug sensitivity/resistance are complex, and their biological significance is not readily interpretable (9). Further experiments are therefore needed to test how the candidate genes affect the TMZ response in malignant glioma cells in vitro, and it is also important to determine whether modulation of the proteins encoded by these genes can enhance the treatment efficacy in patients with TMZ resistant malignant gliomas.

\section{Acknowledgements}

This work was supported in part by Grants-in-Aid for Scientific Research from the Japan Society for the Promotion of Science (grant no. 19591706 and 19591707).

\section{References}

1. Stupp R, Mason WP, van den Bent MJ, et al: Radiotherapy plus concomitant and adjuvant temozolomide for glioblastoma. $\mathrm{N}$ Engl J Med 352: 987-996, 2005.

2. Stupp R, Hegi ME, Mason WP, et al: Effects of radiotherapy with concomitant and adjuvant temozolomide versus radiotherapy alone on survival in glioblastoma in a randomized phase III study: 5-year analysis of the EORTC-NCIC trial. Lancet Oncol 10: 459-466, 2009.

3. Friedman HS, Kerby T and Calvert H: Temozolomide and treatment of malignant glioma. Clin Cancer Res 5: 2585-2597, 2000.

4. Maxwell JA, Johnson SP, McLendon RE, et al: Mismatch repair deficiency does not mediate clinical resistance to temozolomide in malignant glioma. Clin Cancer Res 14: 4859-4868, 2008.
5. Augustine CK, Yoo JS, Potti A, et al: Genomic and molecular profiling predicts response to temozolomide in melanoma. Clin Cancer Res 15: 502-510, 2009.

6. Auger N, Thillet J, Wanherdrick K, et al: Genetic alterations associated with acquired temozolomide resistance in SNB-19, a human glioma cell line. Mol Cancer Ther 5: 2182-2192, 2006.

7. Kaina B and Christmann M: DNA repair in resistance to alkylating anticancer drugs. Int J Clin Pharmacol Ther 40: 354-367, 2002.

8. Bredel M, Bredel C, Juric D, et al: Tumor necrosis factor-alphainduced protein 3 as a putative regulator of nuclear factorkappaB-mediated resistance to $O^{6}$-alkylating agents in human glioblastoma. J Clin Oncol 24: 274-287, 2006.

9. Staunton JE, Slonim DK, Coller HA, et al: Chemosensitivity prediction by transcriptional profiling. Proc Natl Acad Sci USA 98: 10787-10792, 2001.

10. Potti A, Dressman HK, Bild A, et al: Genomic signatures to guide the use of chemotherapeutics. Nat Med 12: 1294-1300, 2006.

11. Takahashi Y, Nagata T, Ishii Y, Ikarashi M, Ishikawa K and Asai S: Up-regulation of vitamin D3 up-regulated protein 1 gene in response to 5-fluorouracil in colon carcinoma SW620. Oncol Rep 9: 75-79, 2002.

12. Blalock EM, Chen KC, Sharrow K, Herman JP, Porter NM, Foster TC and Landfield PW: Gene microarray in hippocampal aging: statistical profiling identifies novel processes correlated with cognitive impairment. J Neurosci 23: 3807-3819, 2003.

13. Pegg AE: Mammalian $O^{6}$-alkylguanine-DNA alkyltransferase: regulation and importance in response to alkylating carcinogenic and therapeutic agents. Cancer Res 50: 6119-6129, 1990.

14. Pegg AE, Dolan ME and Moschel RC: Structure, function, and inhibition of $O^{6}$-alkylguanine-DNA alkyltransferase. Prog Nucleic Acid Res Mol Biol 51: 167-223, 1995.

15. Gerson SL: Clinical relevance of $M G M T$ in the treatment of cancer. J Clin Oncol 20: 2388-2399, 2002.

16. Herman JG, Graff JR, Myöhänen S, Nelkin BD and Baylin SB: Methylation-specific PCR: a novel PCR assay for methylation status of CpG island. Proc Natl Acad Sci USA 93: 9821-9826, 1996.

17. Esteller M, Hamilton SR, Baylin SB and Herman JG: Inactivation of the DNA repair gene $O^{6}$-methylguanine-DNA methyltransferase by promoter hypermethylation is a common event in primary human neoplasia. Cancer Res 59: 793-797, 1999.

18. Komine C, Watanabe T, Katayama Y, Yoshino A, Yokoyama T and Fukushima T: Promoter hypermethylation of the DNA repair gene $O^{6}$-methylguanine-DNA methyltransferase is an independent predictor of shortened progression free survival in patients with low-grade diffuse astrocytomas. Brain Pathol 13: 176-184, 2003.

19. Watanabe T, Katayama Y, Ogino A, Ohta T, Yoshino A and Fukushima T: Preliminary individualized chemotherapy for malignant astrocytoma based on $O^{6}$-methylguanine-deoxyribonucleic acid methyltransferase methylation analysis. Neurol Med Chir 46: 387-394, 2006.

20. Tanaka S, Kobayashi I, Oka H, Fujii K, Watanabe T, Nagashima T and Hori T: $O^{6}$-methylguanine-DNA methyltransferase gene expression in gliomas by quantitative real-time RT-PCR and clinical response to nitrosoureas. Int J Cancer 103: 67-72, 2003.

21. Tanaka S, Oka H, Fujii K, Watanabe K, Nagao K and Kakimoto A: Quantitation of $O^{6}$-methylguanine-DNA methyltransferase gene messenger RNA in gliomas by means of realtime RT-PCR and clinical response to nitrosoureas. Cell Mol Neurobiol 25: 1067-1071, 2005.

22. Yachi K, Watanabe T, Ohta T, et al: Relevance of MSP assay for the detection of $M G M T$ promoter hypermethylation in glioblastomas. Int J Oncol 33: 469-475, 2008.

23. Yoshino A, Ogino A, Yachi K, et al: Effect of INF-B on human glioma cell lines with temozolomide resistance. Int J Oncol 35: 139-148, 2008.

24. Maglott D, Ostell J, Pruitt KD and Tatusova T: Entrez gene: gene-centered information at NCBI. Nucleic Acids Res 35: D26-D31, 2007.

25. Davoust N, Wion D, Chevalier G, Garabedian M, Brachet P and Couez D: Vitamin D receptor stable transfection restores the susceptibility to 1,25-dihydroxyvitamin D3 cytotoxicity in a rat glioma resistant clone. J Neurosci Res 52: 210-219, 1998.

26. Diesel B, Radermacher J, Bureik M, et al: Vitamin D3 metabolism in human glioblastoma multiforme: functionality of CYP27B1 splice variants, metabolism of calcidiol, and effect of calcitriol. Clin Cancer Res 11: 5370-5380, 2005. 
27. Lapointe M, Lanthier J, Moumdjian R, Régina A and Desrosiers RR: Expression and activity of L-isoaspartyl methyltransferase decrease in stage progression of human astrocytic tumors. Brain Res Mol Brain Res 135: 93-103, 2005.

28. Mirkin BL, Clark S, Zheng X, Chu F, White BD, Greene M and Rebbaa A: Identification of midkine as a mediator for intercellular transfer of drug resistance. Oncogene 24: 4965-4974, 2005.

29. Mashima T, Sato S, Sugimoto Y, Tsuruo T and Seimiya H: Promotion of glioma cell survival by acyl-CoA synthetase 5 under extracellular acidosis conditions. Oncogene 28: 9-19, 2009.

30. Scherf U, Ross DT, Waltham M, et al: A gene expression database for the molecular pharmacology of cancer. Nat Genet 24: $227-235,2000$.

31. Trivedi RN, Almeida KH, Fornsaglio JL, Schamus S and Sobol RW: The role of base excision repair and the sensitivity and resistance to temozolomide-mediated cell death. Cancer Res 65: 6394-6400, 2005.

32. Friedman HS, Johnson SP, Dong O, et al: Methylator resistance mediated by mismatch repair deficiency in a glioblastoma multiforme xenograft. Cancer Res 57: 2933-2936, 1997.

33. Hegi ME, Diserens AC, Gorlia T, et al: MGMT gene silencing and benefit from temozolomide in glioblastoma. N Engl J Med 352: 997-1003, 2005.

34. Paz MF, Yaya-Tur R, Rojas-Marcos I, et al: CpG island hypermethylation of the DNA repair enzyme methyltransferase predicts response to temozolomide in primary gliomas. Clin Cancer Res 10: 4933-4938, 2004.

35. Watanabe T, Katayama Y, Komine C, Yoshino A, Ogino A Ohta T and Fukushima T: O6-Methylguanine-DNA methyltransferase methylation and TP53 mutation in malignant astrocytomas and their relationship with clinical course. Int J Cancer 113: 581-587, 2005

36. Drablos F, Feyzi E, Aas PA, et al: Alkylation damage in DNA and RNA-repair mechanisms and medical significance. DNA Repair (Amst) 3: 1389-1407, 2004.

37. Györffy B, Surowiak P, Kiesslich O, Schäfer R, Dietel M and Lage H: Gene expression profiling of 30 cancer cell lines predicts resistance towards 11 anticancer drugs at clinically achieved concentrations. Int J Cancer 118: 1699-1712, 2006.

38. Zhang JT: Use of array to investigate the contribution of ATPbinding cassette transporters to drug resistance in cancer chemotherapy and prediction of chemosensitivity. Cell Res 17: $311-323,2007$
39. Ma J, Murphy M, O'Dwyer PJ, Berman E, Reed K and Gallo JM: Biochemical changes associated with a multidrug-resistant phenotype of a human glioma cell line with temozolomideacquired resistance. Biochem Pharmacol 63: 1219-1228, 2002.

40. Kanzawa T, Bedwell J, Kondo Y, Kondo S and Germano IM: Inhibition of DNA repair for sensitizing resistant glioma cells to temozolomide. J Neurosurg 99: 1047-1052, 2003.

41. Natsume A, Ishii D, Wakabayashi T, Tsuno T, Hatano H, Mizuno $\mathrm{M}$ and Yoshida J: IFN- $\beta$ down-regulates the expression of DNA repair gene $M G M T$ and sensitizes resistant glioma cells to temozolomide. Cancer Res 65: 7573-7579, 2005.

42. Quinn JA, Jiang SX, Reardon DA, et al: Phase II trial of temozolomide plus $\mathrm{O}^{6}$-benzylguanine in adults with recurrent, temozolomide-resistant malignant glioma. J Clin Oncol 10: 1262-1267, 2009

43. Wang CY, Cusack JC Jr, Liu R, et al: Control of inducible chemoresistance: enhanced anti-tumor therapy through increased apoptosis by inhibition of NF-kappaB. Nat Med 5: 412-417, 1999.

44. Nakanishi $\mathrm{C}$ and Toi M: Nuclear factor-kappaB inhibitors as sensitizers to anticancer drugs. Nat Rev Cancer 5: 297-309, 2005.

45. Weaver KD, Yeyeodu S, Cusack JC, Baldwin AS Jr and Ewend MG: Potentiation of chemotherapeutic agents following antagonism of nuclear factor kappa B in human gliomas. J Neurooncol 61: 187-196, 2003.

46. Murat A, Migliavacca E, Gorlia T, et al: Stem cell-related 'selfrenewal' signature and high epidermal growth factor receptor expression associated with resistance to concomitant chemoradiotherapy in glioblastoma. J Clin Oncol 26: 3015-3024, 2008.

47. Stupp R, Dietrich PY, Ostermann Kraljevic S, et al: Promising survival for patients with newly diagnosed glioblastoma multiforme treated with concomitant radiation plus temozolomide followed by adjuvant temozolomide. J Clin Oncol 20: 1375-1382, 2002.

48. Bacolod MD, Lin SM, Johnson SP, Bullock NS, Colvin M, Bigner DD and Friedman HS: The gene expression profiles of medulloblastoma cell lines resistant to preactivated cyclophosphamide. Curr Cancer Drug Targets 8: 172-179, 2008. 